\title{
Considerations on Forest Changes of Northwest China in Past Seven Decades
}

\author{
Yang Guojing ${ }^{1}$, Li Junhao ${ }^{1}$ and Zhou Lihua ${ }^{2,3 *}$ \\ ${ }^{1}$ Key Laboratory of Eco-Hydrology of Inland River Basin, Northwest Institute of Eco-Environment and Resources, Chinese \\ Academy of Sciences, Lanzhou, China, ${ }^{2}$ Institutes of Science and Development, Chinese Academy of Sciences, Beijing, China, \\ ${ }^{3}$ School of Public Policy and Management, University of Chinese Academy of Sciences, Beijing, China
}

\section{OPEN ACCESS}

Edited by:

Atsushi Tsunekawa,

Tottori University, Japan

Reviewed by:

Elzbieta Antczak,

University of Łódź, Poland

Neil A. Coles,

University of Leeds, United Kingdom

*Correspondence:

Zhou Lihua

Ihzhou@casisd.cn

Specialty section:

This article was submitted to

Land Use Dynamics,

a section of the journal

Frontiers in Environmental Science

Received: 31 July 2020

Accepted: 04 May 2021

Published: 08 June 2021

Citation:

Guojing $Y$, Junhao L and Lihua Z (2021) Considerations on Forest Changes of Northwest China in Past

Seven Decades.

Front. Environ. Sci. 9:589896. doi: 10.3389/fenvs.2021.589896
Forests cover four billion hectares (31\%) of the Earth's landmass and contain over $75 \%$ of all carbon in vegetation. They provide renewable raw materials and natural amenities, protect land and water resources, harbor biological diversity, and mitigate climate change. However, due to less precipitation, the forest coverage rate is only $5.86 \%$ in Northwest China. The forests in these arid areas are mainly distributed in alpine areas, which play a key role in runoff regulation and ensure the ecological and economic development of the middle and lower reaches of the inland basins. In the past several decades, China had experienced large-scale deforestation and reforestation. What were the changes of the few forest areas and growing stock in arid Northwest China? Has forest quality been restored? Changes of that had been analyzed in this article. The results showed that the forest area and growing stock decreased greatly from the 1950s to 1970s; the artificial forest area increased clearly; the natural forest area stabilized from the 1980s, growing stock of forest per unit area was still lower than that in the 1950s; and the forest quality had not yet been restored. Results of the analysis of influencing factors showed that the policy-led human activities in different periods were the efficient cause of forest changes in Northwest China. With the development of forestry science, more and more attention has been paid to forest ecological restoration. "Three-North Shelter Forest Program (TNSFP)" in 1978 had made great progress on forest areas by afforestation, and the ecological benefits and economic benefits also increased remarkably owing to the increase in the artificial forest area. In recent years, great progress on forest areas has been made by afforestation, and the forests also contribute significantly to the ecology and economy. However, large-scale afforestation in the Loess Plateau had caused a phenomenon of large investment and little effect on water conservation in some afforestation areas, which showed that afforestation initiated under different polices, which were not always scientifically based, resulted in unintended consequences. Clear ecological principles should be used to ensure best environmental and forest ecology outcomes.

Keywords: forest changes, forest area, forest growing stock, arid Northwest China, forest structure, forest function, ecological principles 


\section{INTRODUCTION}

Forests are the main body and important resource of terrestrial ecosystem, which cover four billion hectares (31\%) of the Earth's landmass and contain over $75 \%$ of carbon in vegetation (F.A.O, 2010). Forests not only provide humans many material products, such as wood, food, energy, and medicinal materials, but also provide abundant ecological services such as carbon sequestration, oxygen release, water conservation, soil and water conservation, air purification, wind and sand fixation, and protection of biological diversity (Shi L. et al, 2011). They could offer humans an important place to enjoy leisure and vacation, ecotourism, and cultural heritage. Therefore, survival, development, and prosperity of mankind can never be separated from the protection and support of forests. Forests are vital to humanity.

The forest coverage rate of China is $22.96 \%$, while the forest coverage rate of Northwest China is only 5.86\% (F.M.O.C, 2019), and it is the lowest compared with northeast, north, south, and southwest China. The forests in Northwest China are mainly concentrated in a few high-altitude areas. In fact, it is because of these forests that the plain areas have a unique and stable water supply, thus ensuring the ecological and economic development of the northwest region, so the forest is the "foundation" of ecological balance and economic development of Northwest China (Wang et al., 2011).

China had experienced large-scale deforestation, reforestation, and afforestation over the past several decades (Wang et al, 2007), and the same happened in Northwest China. From the early 1950s to the late 1970s, the forest in Northwest China suffered deforestation and unreasonable exploitation and utilization, which resulted in the continuous reduction of the forest area, the sharp reduction of forest growth, and even serious ecological disaster. Since the 1980s, the leaders at all levels and government departments have attached great importance to the cultivation of forest resources and vigorously implemented the policies of afforestation and forest retreat. Especially since the implementation of the "Three-North Shelter Forest Program (TNSFP)" in 1978, the forest area and growing stock have increased for nearly 30 years, which had greatly improved the ecological and economic benefits of local areas. The changes of the forest area and growing stock had been analyzed, and the forest quality changes had also been analyzed in this study. The results indicated that growing stock per unit area of natural forest was lower than that in the 1950s. Limited by the precipitation conditions and other factors in Northwest China, the forests are still in the situation of "increasing quantity and unsatisfactory quality." In this study, we used the national forest inventory data of ten time periods (1950-1962, 1973-1976, 1977-1981, 1984-1988, 1989-1993, 1994-1998, 1999-2003, 2004-2008, 2009-2013, and 2014-2018) to evaluate the status and change of the forests in Northwest China over the past seven decades (F.M.O.C, 2004, 2009, 2014, 2019). The results would be conducive to understanding of the dynamic and multifaceted state of forests in Northwest China, which would be of great significance to the development of macropolicy and environmental monitoring.
We knew that forests contribute significantly to the ecology and economy, but it does not mean that the larger the forest area, the more beneficial it is. In the Loess Plateau, the cost of afforestation is too high due to topography and limited precipitation. In recent years, although extensive afforestation in the Loess Plateau has some benefits for soil erosion, it also has adverse effects, resulting in local water shortage in some areas. Therefore, the scientific nature of large-scale afforestation policies in some areas should be carefully considered, and clear ecological principles should be used to ensure best environmental and forest ecology outcomes.

\section{FOREST DISTRIBUTION AND STRUCTURAL CHARACTERISTICS IN NORTHWEST CHINA}

\section{Small Forest Area and Lower Forest Coverage in Northwest China}

In Northwest China, the annual average precipitation is not more than $400 \mathrm{~mm}$, which seriously limits the growth and development of forests in this region. As we all know, the demand for forest tree species for environmental temperature and water supply is high, forests are generally distributed in the areas where the hottest monthly mean temperature is not less than $10^{\circ} \mathrm{C}$ and the annual precipitation is not less than $400 \mathrm{~mm}$ (He. Q.T. 1999). In Northwest China, although the heat conditions are sufficient, water availability is not enough to make the forests grow. Therefore, most of the forests in Northwest China are distributed in high mountains and abundant river valleys, or in areas with sufficient groundwater supply. In Northwest China, there is only about 27.18 million ha of the forest area, and the forest coverage rate is $8.72 \%$. Among them, there are more than $70 \%$ of natural forests distributed in a few mountainous areas with much precipitation (F.M.O.C. 2009). Figure 1 and Table 1 clearly show the characteristics of forest distribution in Northwest China.

From the perspective of each administrative region, the forest coverage rate of Shaanxi Province is higher than the national average, and all other northwest provinces and regions have lower than $12 \%$ of forest coverage rate (Table 1). Especially, the forest coverage rate of Xinjiang is only $4.87 \%$, which is the lowest in China (F.M.O.C. 2009).

\section{Natural Forests Distributed in High Mountain Areas With High Growing Stock}

The natural forests in the northwestern region are mainly distributed in the southern slopes of the Qinling Mountains (Hanzhong Prefecture, Bailong River Basin), Mount Tianshan, the Altai Mountains, Qilian Mountains, and the southeastern part of Qinghai. These are the original alpine forest areas and are distributed by the state-owned forestry bureaus (Table 2). Secondary forest areas include Shaanxi, Ganzi East (Xiaolong Mountain, Ziwuling), Huanglong Mountain, and Bridge Mountain. Natural forests account for the largest proportion of middle-aged forests (29.90\%), followed by near-mature 


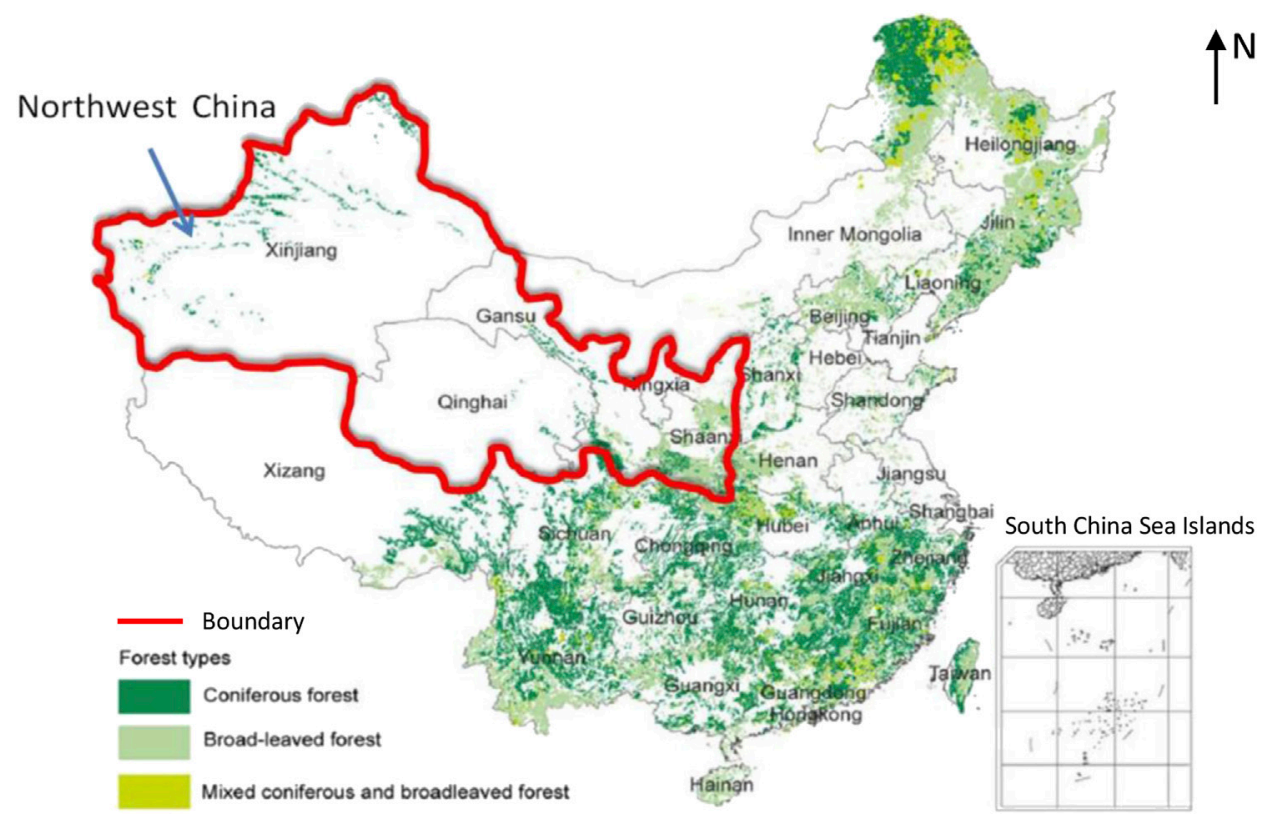

FIGURE 1 | Forest distribution in Northwest China based on the data of the sixth forest inventory (1999-2003). Forests are grouped into three types: coniferous forest, broad-leaved forest, and coniferous and broad-leaved mixed forest. The background map shows the administrative divisions of China. doi:10.1371/journal.pone. 0020778.9001.

TABLE 1 | Forest area and growing stock in Northwest China.

\begin{tabular}{|c|c|c|c|c|}
\hline Province & $\begin{array}{c}\text { Land area } \\
{\left[1 \times 10^{6} \text { ha }\right.} \\
\text { (F. M. O. C. }(2019)]\end{array}$ & $\begin{array}{c}\text { Forest area } \\
{\left[1 \times 10^{6} \text { ha }\right.} \\
\text { (F. M. O. C. }(2019)]\end{array}$ & $\begin{array}{l}\text { Forest growing stock } \\
{\left[1 \times 10^{8} \mathrm{~m}\right.} \\
(\text { Chen, 2007)] }\end{array}$ & $\begin{array}{c}\text { Forest } \\
\text { coverage rate }(\%)\end{array}$ \\
\hline Shaanxi & 20.58 & 8.86 & 5.10 & 43.06 \\
\hline Ningxia & 6.64 & 0.84 & 1.11 & 12.63 \\
\hline Gansu & 45.37 & 5.14 & 2.84 & 11.33 \\
\hline Qinghai & 73.10 & 4.25 & 0.56 & 5.82 \\
\hline Xinjiang & 166 & 8.08 & 4.65 & 4.87 \\
\hline Northwest China & 311.69 & 27.18 & 14.26 & 8.72 \\
\hline China & 960 & 220.44 & 190.07 & 22.96 \\
\hline
\end{tabular}

Data from the ninth forest inventory (2014-2018).

TABLE 2 | Major alpine forest areas and forest types in Northwest China.

\section{Main mountain natural \\ forest area}

\section{Forest area \\ $\left[1 \times 10^{4}\right.$ ha (Huang. 2012)]}

\section{Altitude} distribution of forests $(m)$

Coniferous forest on the northern slope of Tianshan Mountain Coniferous forest on the southwest slope of the Altai Mountains Coniferous forest on the northern slope of Qilian Mountain

Coniferous and broad-leaved mixed forest in Qinling Mountain

Holan mountain forest area

$\begin{array}{ccc}253 & 1,600 \sim 2,700 & 420 \\ 225 & 1,500 \sim 600 & 470 \\ 43.6 & 2,300 \sim 3,600 & 500 \\ 317 & 600 \sim 3,500 & 800 \sim 1,200 \\ 22.9 & 2,000 \sim 3,000 & 420\end{array}$

\section{Precipitation in the forest} regions $(\mathrm{mm})$

420
Main dominant species

\author{
P. schrenkiana Fischet Mey \\ Abies sibirica, Larix sibirica Ledeb \\ Picea crassifolia Kom, Sabina przewalskii Komr
}

Quercus acutissima Carruth, Quercus variabilis Bl, Betula albosinensis Burk, Abies fargesii Franch, Larix olgensis Henry, bamboo grove

Pinus tabuliformis Carr, Picea crassifolia Kom 
forests (19.45\%). The forest area with the medium canopy closure $(0.5-0.7)$ is the largest in the forest canopy closure, accounting for $56.76 \%$, followed by sparse forest $(0.2-0.4)$, accounting for $31.50 \%$; the natural forest also has relatively high accumulations per unit area $\left(125.56 \mathrm{~m}^{3} \mathrm{ha}\right)$ and has strong ecological functions such as carbon sequestration and oxygen release, and and soil and water conservation.

\section{Riparian Forests Along Inland Rivers With Simple Structure and Dominant Species of Sandy and Halophytes}

There are large areas of Populus euphratica forest or Haloxylon ammodendron forest along the inland river in Northwest China. The riverside Populus euphratica forests were concentrated along the Tarim and Heihe rivers in southern Xinjiang, forming corridor-like riparian forests. Its climate is characterized by extreme drought in the middle temperate zone and warm temperate zone. The average annual temperature is $10-11^{\circ} \mathrm{C}$, which is greater than or equal to the accumulated annual temperature of $10^{\circ} \mathrm{C} \quad 4,000-4,300^{\circ} \mathrm{C}$, and the annual precipitation is $25-50 \mathrm{~mm}$, and the evaporation is 2,000-3,000 mm. The growth of Populus euphratica forest is basically separated from the effects of natural precipitation and surface water, mainly relying on flooding and groundwater to survive. Populus euphratica forest is simple in composition, simple in structure, and characterized by the Central Asian desert. They are dominated by xerophytes, psammophytes, and halophytes (Wu, 1980). Common vegetation types are Populus euphratica, gray willows, Tamarix multibranched, Elaeagnus angustifolia, licorice, camel thorn, Nitraria, Lycium ruthenicum, and Halostachys caspica, among which Compositae is the most common, followed by Leguminosae, Tamarix, Chenopodiaceae, etc. In addition to a large area of alpine forests and riparian forests along the inland rivers, the area of artificial forest is also increasing under the development of the TNSFP in the northwestern region, mainly distributed around the cultivated land, with the main purpose acting as wind breaks and stabilizing the soils.

\section{FOREST CHANGES IN NORTHWEST CHINA IN RECENT SEVEN DECADES}

\section{Forest Area and Growing Stock Decreasing From the 1950 to 1970 s and Increasing After 1980s}

It was reported that from the early 1950s to the late 1970s, the policies of "steel-making" and "seeking grain from barren mountains" during the historical period of "the Great Leap Forward" resulted in the rush of deforestation and grassland reclamation for many years in Northwest China, resulting in the loss of natural forest resources in Northwest China (Li B.C. 2000). And then, in the past few decades since the 1980s, driven by the economic interests, deforestation and grassland destruction had begun in some provinces, again leading to a reduction in the forest area. Inappropriate policies led to a variety of irrational forest development, leading to a decline in the forest area and growing stock, reaching the lowest level in the early 1980s (Figures 2, 3).

On the basis of previous analysis of national forest inventory data, the area of forest in Northwest China decreased from 11.87 million ha (F. M. O. C. 2004) in the 1950s to 10.8 million ha (F. M. O. C. 2009) in the late 1970s, and decreased by nearly 1.1 million $\mathrm{hm}$ in 30 years. The growing stock also decreased from $6.5 \times 10^{8} \mathrm{~m}^{3}$ in the 1950 s to $5.3 \times$ $10^{8} \mathrm{~m}^{3}$ in the late $1970 \mathrm{~s}$ and decreased $1.2 \times 10^{8} \mathrm{~m}^{3}$ in the past 30 years. Compared with the economic value of forests, forests in Northwest China played a more significant role in maintaining ecological balance and ensuring the safety of environment security in Northwest China. The loss of forest resources had aggravated soil erosion, water shortage, climate deterioration, desert expansion, landslides, and debris flow disasters in Northwest China. The comprehensive effect of these factors made the social economy and culture of Northwest China more backward and posed a great challenge to the living environment of the people of all nationalities in Northwest China. The ecology and economics in Northwest China had paid a huge price for these policies.

Since the 1980s, the absolute amount of the forest area and growing stock in Northwest China has increased in the past 40 years of reform and opening up. The forest area increased from $10.9 \times 10^{6}$ ha in 1977 to $26.8 \times 10^{6}$ ha (F. M. O. C. 2019) in 2018 and increased by $15.9 \times 10^{6}$ ha in 40 years (Figure 2 ). The growing stock also increased from $5.07 \times 10^{8} \mathrm{~m}^{3}$ in 1977 to $13.21 \times 10^{8} \mathrm{~m}^{3}$ in 2018 and increased by $8.14 \times 10^{8} \mathrm{~m}^{3}$ in 40 years. However, in terms of the proportion of natural forests and artificial forests, the main reason for the increase in the forest area in the recent 40 years was the increase in the proportion of artificial forest. The results of the forestry inventory in the early days of the founding of New China showed that the areas and growing stock proportion of natural forests in the northwestern region were 95.3 and $99.5 \%$. By 2018, the proportion of natural forests decreased to 64.1 and $91.3 \%$, and the proportion of area and growing stock continued to decline, and the proportion of artificial forest areas and growing stock continued to rise (Figures 4, 5). Therefore, the increase in the forest area and growing stock were mainly caused by large-scale afforestation after the 1980s.

\section{Un-Restored Quality and Ecological Benefits of Forest in Northwest Chinese}

The quality of forest is essential for maintaining and increasing forest resources, and the forest quality status is directly related to the effectiveness of forests, which is as important as forest coverage. According to the changes of the forest structure in Northwest China, before the 1970s, the area and growing stock proportion of coniferous forests were 72.8 and $77.3 \%$, respectively, which were higher (Figures 6, 7); From the 1980s to 2003, the area ratio of coniferous and broad-leaved forest was close to 1:1, the stock volume of coniferous forest was dominant, but the proportion decreased from 77.3 to $53.9 \%$; after that, the 


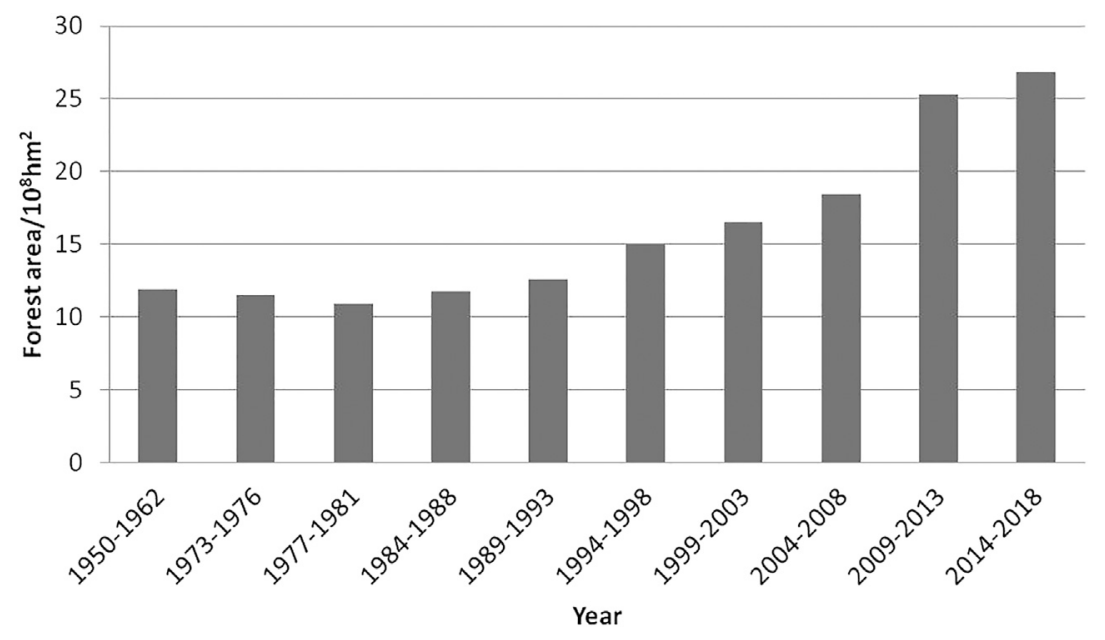

FIGURE 2 | Forest area changes in Northwest China.

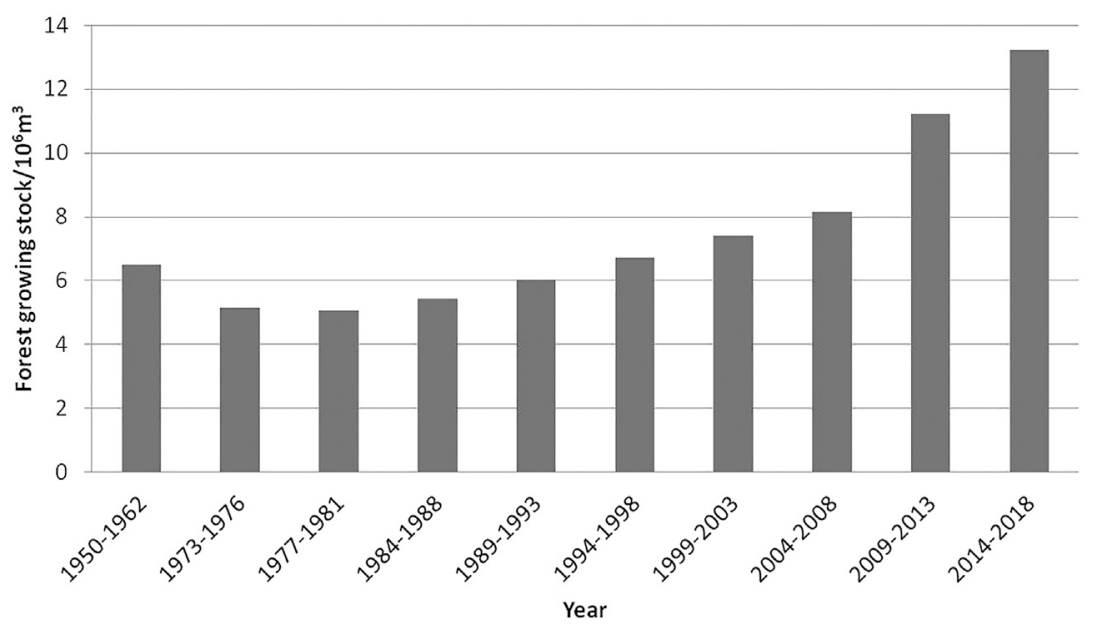

FIGURE 3 | Forest growing stock changes in Northwest China.

proportion rose slowly to $59.03 \%$ in 2018 . It can be observed that the coniferous forest harvesting significantly reduced the forest area during the period from 1977 to 1981 . And after the 1980s, the conservation policies had the coniferous forest gradually restored.

In terms of the actual change areas of forest age-groups, the area of young and medium forest basically showed a trend of increasing. By 2018, the area of sapling and half-mature forests was 1.5 and 2.9 times that in 1950, respectively. The area of mature/ancient forests decreased significantly from 1950 to 1981, which was only $61 \%$ of that in 1950 . From 1982 to 2018, the area of mature/ancient forests increased gradually. Compared with 1950 , the proportion of the sapling forest area changed slightly in 2018 , from 34.4 to $33.6 \%$; the proportion of the half-mature forest area increased from 18.6 to $38.3 \%$; the proportion of the mature/ ancient forest area decreased significantly from 46.9 to $28.1 \%$, and the lowest value was $28.8 \%$ in 1989 (Figure 8). This indicated that artificial afforestation and natural regeneration had ensured that the area of sapling forests was not reduced, while the cutting speed of mature/ancient forests was obviously higher than the natural ripening speed of half-mature forests. The change trends of forest growing stock of different age-groups were similar to the change trend of forest area, but the growing stock of forest per unit area was lower than that in 1950s. From the analysis of the proportion of the growing stock of each age-group of the forests, the growing stock of mature/ancient forests was always accounted for the main part of the growing stock of the forests, which was $81.3 \%$ in 1950 and reduced to $58.7 \%$ in 2018 . The proportion of growing stock of sapling forests and half-mature forests increased significantly, from 5.7 to $13 \%$ in 1950 to 12.1 and $32.7 \%$ in 2009 , respectively (Figure 9). Obviously, after 1981, the forest area and total growing stock in Northwest China increased greatly, but the main reason was the increase in the plantation area, and mainly 


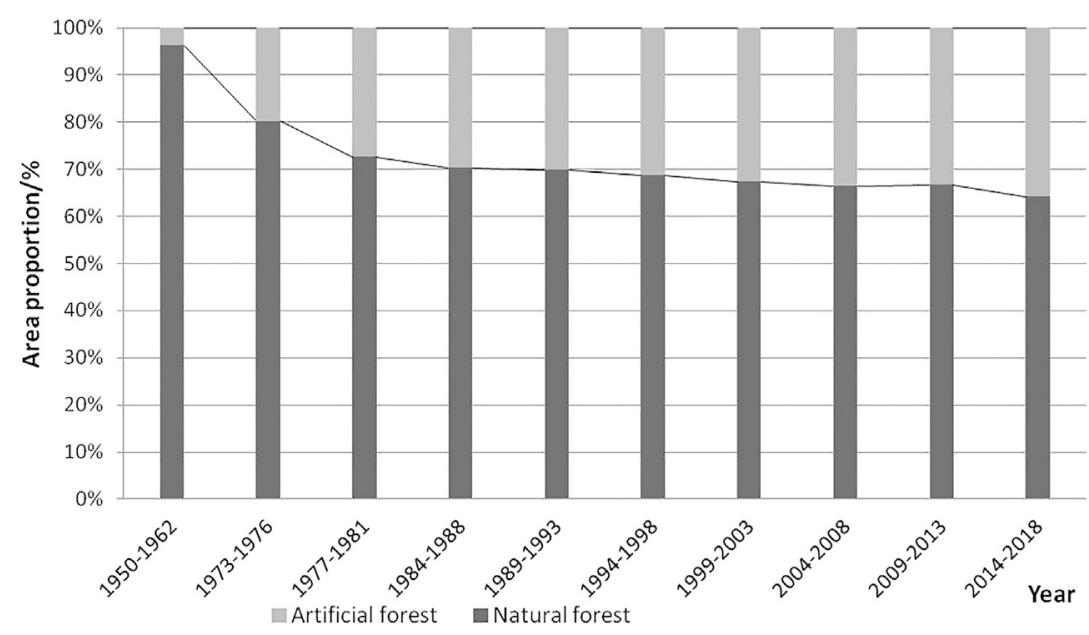

FIGURE 4 | Forest area proportion of artificial forest and natural forest.

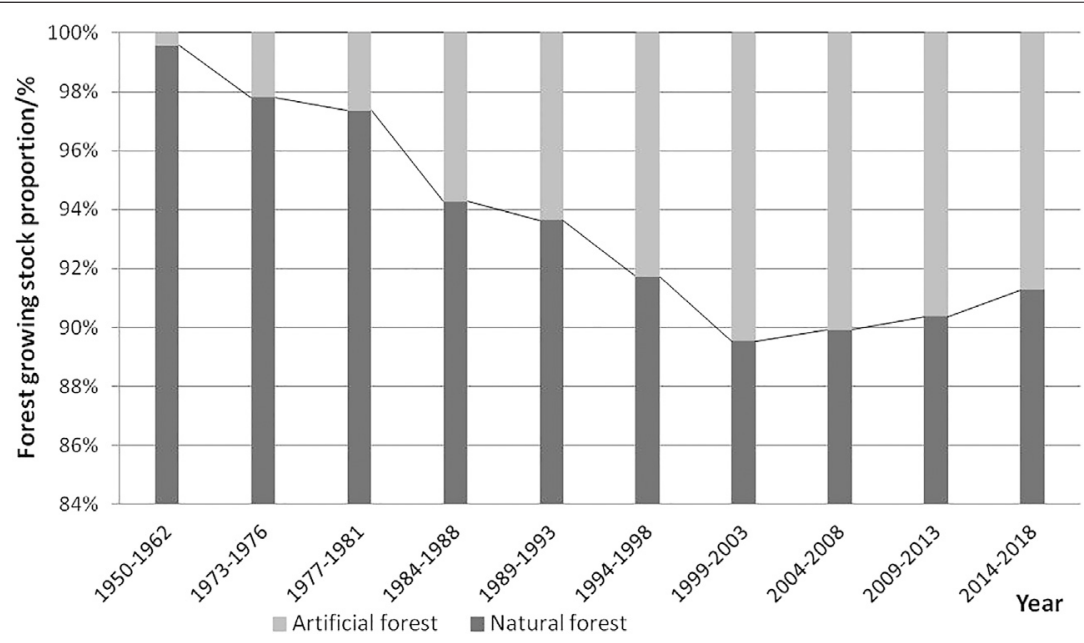

FIGURE 5 | Forest growing stock proportion of artificial forest and natural forest.

the increase of sapling forests and half-mature forests area and growing stock.

\section{INFLUENCING FACTORS OF FOREST CHANGES IN NORTHWEST CHINA}

\section{Impact of Misguided Policies on Forests}

In the mid-1950s, the "grain-based" approach to development had resulted in extensive deforestation and wasteland reclamation, seriously destroying the national forest resources, including the forests in Northwest China. And after that, in 1960s, large-scale immigration activities such as excessive agricultural reclamation and forestry development greatly destroyed the wellpreserved natural forests. The series of misguided development policies had lasted almost 20 years and directly led the reduction of forest areas and growing stock. It was not until the late 1970s that the national forestry sector realized the mistakes and began to protect forests and plant trees, which resulted in the increase of forests. Therefore, the implementation of different policies was the main direct cause of the forest changes in past several decades.

\section{Impact of Rapid Population Growth on Forest Resources}

The explosive growth of population had brought a series of difficulties to mankind and also brought serious harm to the ecological environment. It was manifested in the continuous reclamation of wasteland and deforestation in order to meet the needs of food, housing, and fuel under the pressure of population explosion. Population growth showed constant negative pressure, population density was significantly 


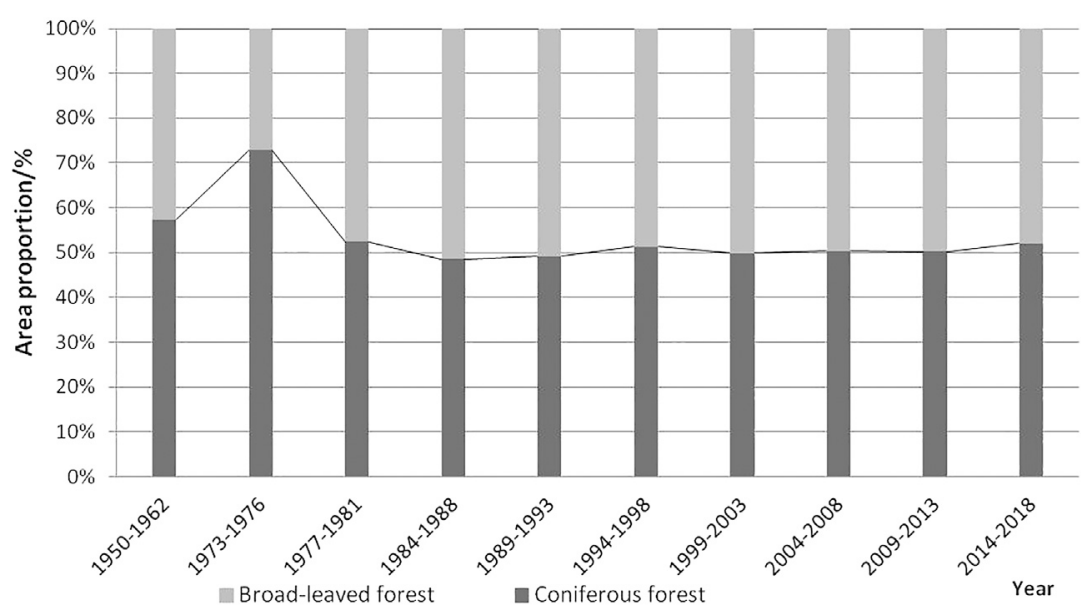

FIGURE 6 | Forest area proportion of broad-leaved forest and coniferous forest.

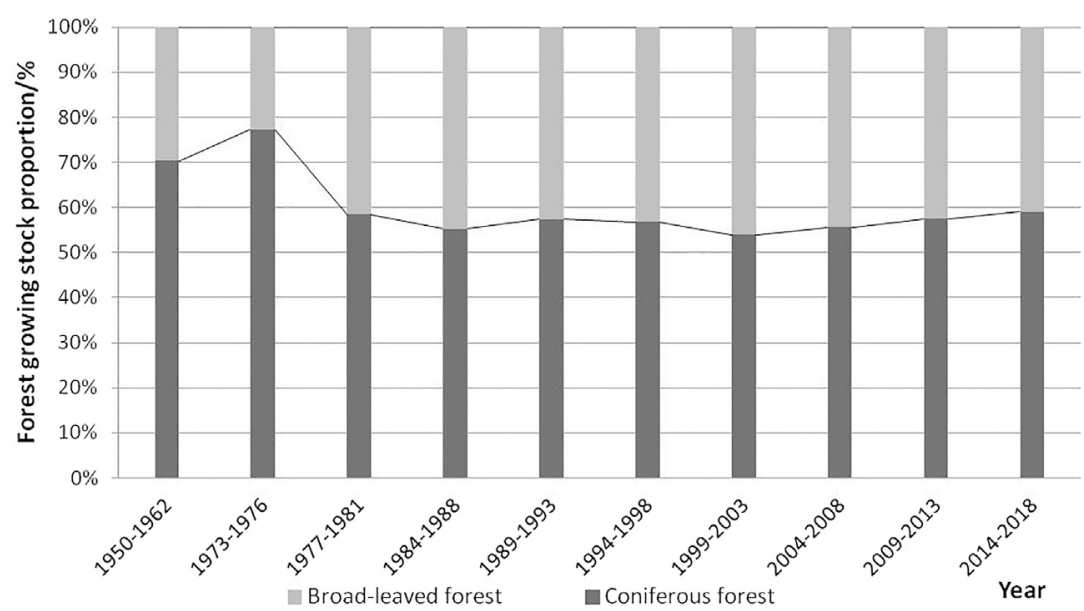

FIGURE 7 | Forest growing stock proportion of broad-leaved forest and coniferous forest.

correlated with deforestation rate, and the correlation coefficient was 0.65 in China (Chen X.Q. 2007). The social burden of stateowned forest industry enterprises and large-scale land development were the leading factors causing the destruction of natural forests (Li L.P. 2011; Bie Q. et al., 2013).

\section{Impact of Forest Property Right and Management Systems on Forest Resources}

In the past 30 years, the state-owned forest areas had changed slowly in the process of economic system reform. The rigid system of forest land property rights restricted the effective utilization of the most abundant capital elements in the stateowned forest areas, and the industrial structure was too concentrated on the utilization of forest products. Furthermore, there were no practical measures to evaluate the restoration and protection of forest resources (Wang and LI.,
2010; Wang et al., 2014). All these limited the further development of forest resources.

\section{Impact of Education, Science, and Technology on Forest Resources}

The education level of the people in a country or region also affects the development of forestry, which has a great relationship with the scientific education environment. Advances in science and technology would contribute to improve the efficiency of forest resources utilization and would also improve the level of forest management and protection, thereby improving the quantity and quality of forest resources. However, the level of science and technology education in Northwest China was generally backward, and the arid climate itself was not conducive to the restoration and development of forest vegetation, and the high investment cost of forestry 


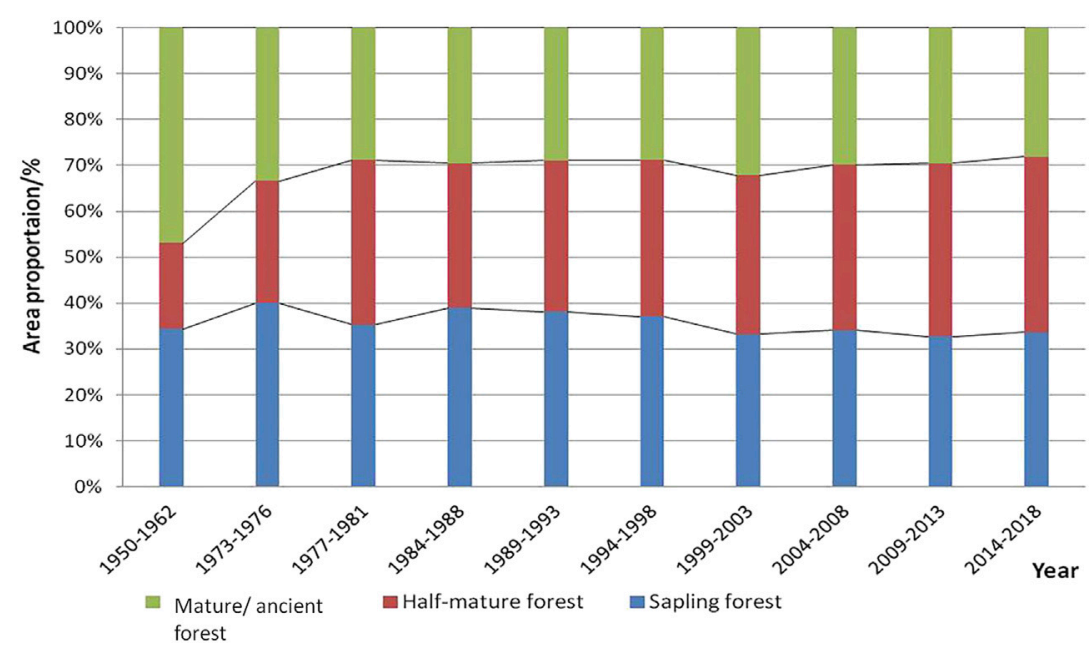

FIGURE 8 | Forest area proportion of different age-groups.

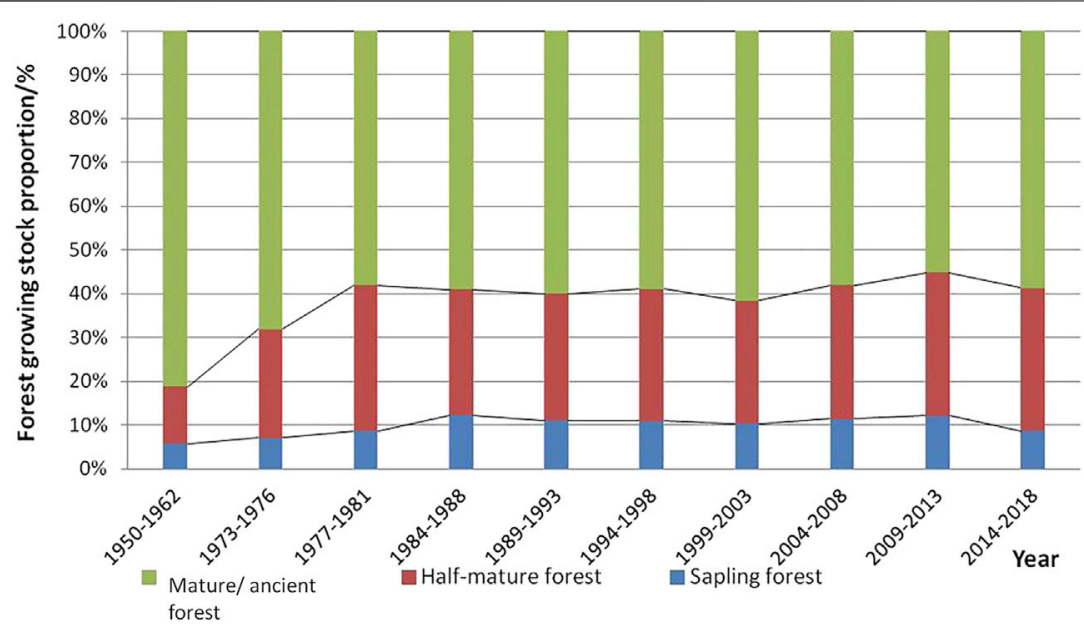

FIGURE 9 | Forest growing stock proportion of different age-groups.

development was also not conducive to the active participation of social forces. These directly affected the prevention of forest fires and forest pest control, and thus affected the normal growth of forests.

\section{CONSIDERATIONS ON FOREST DEVELOPMENT IN NORTHWEST CHINA}

Large-scale afforestation might bring some advantages and also had adverse effects. On the one hand, the increase of the forest area would be beneficial to improve the ecological environment to a certain extent, which could be demonstrated by the TNSFP. On the other hand, unreasonable afforestation in large areas would cause economic waste and even lead to other ecological problems.

\section{Ecological Benefit From the "Three-North Shelter Forest Program"}

Average annual precipitation is below $400 \mathrm{~mm}$ in most areas of Northwest China, which is not conducive to forest growth. In these areas, forests suffered damage as a result of some natural forces and unreasonable human activities in the past decades, which caused a series of ecological problems, such as desertification, aggravated soil erosion, increasing dust weather, and so on. In Northwest China, the total area of desert and desertification land is 1.49 million $\mathrm{km}^{2}$ (Huang. 2012), and $90 \%$ of the serious soil erosion areas of Loess Plateau are distributed in this region. Chinese government departments attached great importance to improving this situation and economic conditions and approved the major strategic decisions for the development of large-scale shelterbelts, in Northeast, Northwest, and North China in 
November 1978, which was the TNSFP. From then on, there was a great increase in the forest area and growing stock in Northwest China. The area of trees increased from 3.80 million ha (Huang. 2012) in 1977 to 6.43 million ha (Huang. 2012) in 2007, and shrubs increased from 3.38 million ha (Huang. 2012) to 10.14 million ha (Huang. 2012), increasing by 0.7 and 20 times, respectively (S.F.A.C. 2008). The growing stock of forest trees also increased from 370 million $\mathrm{m}^{3}$ in 1977 to 660 million $\mathrm{m}^{3}$ in 2007, an increase of nearly 0.8 times. Forest coverage increased from $2.62 \%$ in 1977 to $6.28 \%$ in 2007 (Ma G.Q. \& Song F., 2015). Over the past decades, the implementation of this measure has significantly increased forest coverage in Northwest China, effectively controlled soil desertification, improved soil erosion and air quality in some areas, and protected biodiversity, which has also brought about certain economic benefits.

\section{Reflections From Afforestation in the Loess Plateau}

In the past ten years, the Loess Plateau, as a key area of soil and water conservation in China, has invested a huge amount of funds, and the local people have also invested in hard-to-measure labor, which has made certain achievements in soil conservation. The latest investigation on soil and water conservation ecology in the Loess Plateau of China showed that the vegetation coverage on the Loess Plateau had increased from $31.6 \%$ in 1999 to $59.6 \%$ in 2013 through vegetation restoration and reconstruction. The average annual sediment discharge of the Yellow River had decreased from 1.6 billion ton to about 300 million ton in 2015 , with a reduction of $80 \%$. Despite that the sediment discharge decreased significantly, the modulus of soil erosion on the Loess Plateau remained between 4,000 and $6,000 \mathrm{t} /[\mathrm{km} \cdot \mathrm{a}]$, and the amount of soil erosion was still more than four times of the allowable value of maintaining ecological security (Zhang S. 2015). The erosion modulus of the Loess Plateau was still not up to the standard, and the problem of soil erosion was still serious. Moreover, after large-scale afforestation in the Loess Plateau, the soil became dry and the runoff decreased (Huang et al, 2012), which may further aggravate the local water shortage, increase the scarcity of already scarce water resources, and may threaten the local and downstream water supply security (Wang Y.H. et al., 2011). Therefore, it was urgent to assess the impact of afforestation on regional water production in the Loess Plateau and to determine reasonable forest coverage in the region (basin) in order to ensure the coordinated development of the region.

\section{Reflection 1: Forest Role in Soil Erosion Control in the Loess Plateau Had Been Overestimated}

With the strengthening of the study on the control of the Loess Plateau, the role of forests in maintaining the ecological balance and preventing soil erosion had been discussed. Some scholars believed that the Loess Plateau originally had dense primitive forests in history, and it was only because the deforestation and land reclamation had destroyed the ecological balance, resulting in the uncontrollable soil erosion. Therefore, they vigorously advocated large-scale afforestation. In fact, according to the geographical location of the Loess Plateau, the zonal law, and the characteristics of the monsoon climate in China, the Loess Plateau is mostly in the transition zone from semiarid to arid areas. Except for the eastern edge of the Loess Plateau and some mountainous areas in the central and western regions, there are small areas of forest due to the influence of topography and much precipitation; most of the other areas belong to semiarid grassland landscape. The annual precipitation in semiarid area is less than $400 \mathrm{~mm}$, which cannot meet the needs of forest growth. The water consumption of artificial forest vegetation reduces the soil moisture content of 3-8 m soil layers in some areas of the Loess Plateau, which is close to or lower than wilting humidity for a long time, forming a deep dry soil layer which is difficult to restore, which would lead to the instability of artificial forest vegetation ecosystem. Some studies had found that afforestation on the Loess Plateau reduced the annual runoff depth by an average of $23 \mathrm{~mm}$. Although the value was not very large, it accounted for $58 \%$ of the annual runoff depth of non-forest land, indicating that large-scale afforestation would cause a significant decrease in runoff yield in the watershed ( $M u$ X. M. et al., 2007). Therefore, a large amount of afforestation investment cannot achieve the function of water conservation but reduced the runoff, making the local water supplies even more strained.

\section{Reflection 2: Machine-Building Terraces Were More Effective in Soil and Water Conservation than Afforestation or Grass Planting in the Loess Plateau}

Mechanized terracing is a method of building terraced fields with bulldozers, requiring less investment and short period, with a quick, effective, and obvious effect of soil and water conservation, and is generally selected for gentle slopes with better site conditions. The investigation showed that the investment of machine-building terraced fields is $¥ 20$-30 per ha, the grain yield per ha would be increased 2-3 times than that of sloping fields, and the investment could be recovered in $4-5$ years. The economic benefits and water and soil conservation benefits were more significant than those of afforestation and grass planting (Yang et al, 2014). At the same time, due to the increase in the yield per ha, 1 ha of terraced fields could be transformed into 1-2 ha of steep slope land accordingly, which could not only improve agricultural productivity but also obtain a good soil and water conservation effect. It is a more effective way of soil and water conservation than afforestation. Besides, in the process of water circulation, the terraced fields make the infiltration of rainfall strengthen rapidly and even make all the rainfall infiltrate into terraced fields in situ. Due to the inherent characteristics of high permeability and high water storage in the Loess Plateau, it would provide a smooth passage for rainfall infiltration. Therefore, the terraced fields could provide abundant water factors for vegetation growth and support the benign development of "hydrology and ecology" (Li S. H. 2011). 


\section{CONCLUSION AND ENLIGHTENMENT}

The status and changes of forests in Northwest China had been assessed on the basis of national forest inventory data of a 10-year period over the past seven decades. From the 1950s to 2018, forests in Northwest China experienced large-scale deforestation and afforestation in the past several decades. The area, growing stock, and structure of forest had changed a lot. The forest area and growing stock decreased pre-1970s and increased significantly since the 1980s due to artificial forest. However, the growing stock of forest per unit area is still lower than that in the 1950s, meaning that the quality of forests and their ecological benefits has not been restored. However, some recent studies showed that large-scale afforestation had also caused other ecological effects. Excessive afforestation in the Loess Plateau had led to soil drying and runoff reduction, threatening water security in local and downstream areas. Main conclusions were as follows:

1) In the past 70 years, the forest area and growing stock in the northwest region had decreased pre 1980s and increased significantly since the 1980s mainly due to the increase of artificial forest. Another reason was that there were different standards of forest canopy cover in forest inventory data in different periods. In order to keep the data consistent, we visited the forestry departments of the counties in study areas and accessed historical information about forest inventory, with their help, the additional forest area and corresponding growing stock added under the new definition for forest were removed. The forest data in this paper were based on the forest canopy cover definition of 1978 (canopy cover $\geq 30 \%$ for forest; canopy cover $\geq 40 \%$ for shrub lands). Although we had tried to remove the impact of the data because of different definition of forest, there must be some influence on the analysis results.

2) "Increasing quantity and unsatisfactory quality" has been the general situation of forest in Northwest China at present. The change of forest composition and structure in Northwest China over the past 70 years showed that the loss of forest in the early stage was mainly caused by the loss of coniferous forest in mountainous areas. The cutting intensity of mature/ancient forests was obviously higher than the natural maturity speed of middle-aged forests, which led to the low growing stock of forest per unit area, single species, poor diversity, and no restoration of forest quality and ecological benefits. Therefore, the protection of natural forests in mountain areas should continue to be strengthened in the future.

3) The ecological benefits of the construction of the "ThreeNorth Shelter Forest Program" project in Northwest China were remarkable. It not only controlled the sandstorm damage in the

\section{REFERENCES}

Bie, Q., Zhao, C. Y., and Qiang, W. L. (2013). Dynamic Change of Picea Crassifolia in Qilian Mountain in Recent 40 Years. J. Arid Land Resour. Environ. 27 (4), 176-180. doi:10.13448/j.cnki.jalre.2013.04.020

Carle, J., Vuorinen, P., and Del Lungo, A. (2002). Status and Trends in Global Forest Plantation Development. For. Prod. J. 52, 12-23. doi:10.1007/s00226-002-0143-7 key control areas but also effectively controlled the serious soil erosion areas in the Loess Plateau. At the same time, it brought some economic benefits. However, recent studies showed that large-scale afforestation on the Loess Plateau had led to soil drying and runoff reduction, threatening water security in local and downstream areas. In the Loess Plateau, the influence of afforestation on regional water production should be evaluated. Clear ecological principles should be used to ensure best environmental and forest ecology outcomes.

4) Although the forest area in Northwest China was small, the effects of water conservation, acting as wind breaks and stabilizing soil, are remarkable. Site conditions, soil environment, and climatic factors suitable for stable forests growth were very restrictive in arid Northwest China. In order to realize the sustainability of forest vegetation restoration, the clear ecological construction principle of "soil and water determine vegetation" must be implemented. In Northwest China, it is urgent to develop forestry development policies adapted to local conditions. Therefore, the scientific nature of large-scale afforestation should be considered.

\section{DATA AVAILABILITY STATEMENT}

The original contributions presented in the study are included in the article/Supplementary Material. Further inquiries can be directed to the corresponding author.

\section{AUTHOR CONTRIBUTIONS}

Conceptualization: YG and ZL. Data curation: YG and LJ. Formal analysis: YG and ZL. Funding acquisition: YG. Methodology: YG. Writing — original draft: YG and LJ. Writing — review and editing: YG and ZL. All authors contributed critically to the drafts and gave final approval for publication.

\section{FUNDING}

This study was financially supported by the Strategic Priority Research Program of the Chinese Academy of Sciences (XDA20020401); the National Natural Science Foundation of China (41671187); the National Key Research and Development Program of China (2018YFA0606402); and the Second Tibetan Plateau Scientific Expedition and Research Program (STEP) (2019QZKK0404).

Chen, X. Q. (2007). The Study on Influence Factors of Regional Forest Resources Fluctuation in China. [dissertation/master's thesis]. [Beijing: Beijing Forestry University].

F.A.O. (2010). Food and Agriculture Organization of the United Nations Global Forests Resources Assessment 2010: Country Report. Rome: Food and Agriculture Organization of the United Nations. Forestry Paper No.163.

F.M.O.C (2004). China's Forest Resources 1999-2003 Report. Beijing: China's Forestry Publishing House. (Chinese Ministry of Forestry) (In Chinese). 
F.M.O.C (2014). China's Forest Resources 2009-2013 Report. Beijing: China's Forestry Publishing House. (Chinese Ministry of Forestry) (In Chinese).

F.M.O.C (2019). China's Forest Resources 2014-2018 Report. Beijing: China's Forestry Publishing House. (Chinese Ministry of Forestry) (In Chinese).

F.M.O.C. (2009). Chinese Ministry of Forestry China's Forest Resources 2004-2008 Report. Beijing: China's Forestry Publishing House. (In Chinese).

He, Q. T. (1999). Forest Environment. Beijing: Higher Education Press.

Huang, S. W., Li, X. S., Wu, B. F., et al. (2012). The Distribution and Drivers of Land Degradation in the Three-North Shelter Forest Region of china during 19822006. Acta Geographica Sinica 67 (5), 589-598. doi:10.11821/xb201205002

Li, L.-p., Liu, Y.-n., Tang, Z.-y., Guo, Z.-d., and Fang, J.-y. (2011). Community Structure and its Affecting Factors of Mountain Coniferous Forests in Xinjiang, China. Arid Zone Res. 28 (1), 31-39. doi:10.3724/sp.j.1148.2011.00031

Li, B. C. (2000). A Study on the Destruction and Change of Forests in Qilian Mountain Area in History. Collections essays Chin. Hist. Geogr. 1, 1-16.

Li, S. H. (2011). Study on Terraced Hydrological Ecology and its effects [dissertation/ doctor's Thesis]. Xi'an: Chang'an University.

Ma, G. Q., and Song, F. (2015). Assessment on the Forest Condition of "Three North" Shelter Forest Area. J. Arid Land Resour. Environ. 18 (5), 108-111.

Mu, X. M., Ba, S. C. L., and Zhang, L. (2007). Impact of Soil Conservation Measures on Runoff and Sediment in Hekou-Longmen Region of the Yellow River. J. Sediment Res. 4 (2), 36-41. doi:10.16239/j.cnki.0468-155x.2007.02.006

Shi, L., Zhao, S., Tang, Z., and Fang, J. (2011). The Changes in China's Forests: An Analysis Using the Forest Identity. PLoS ONE 6 (6), e20778. doi:10.1371/ journal.pone.0020778

The state forestry administration of the People's Republic of China (2008). 30-year Development Report on the Construction of the Three-North Shelterbelt System (1978-2008). Beijing: China Forestry Publishing House.

Wang, D. Q., and Li, G. Q. (2010). Development and Changes of Forest Resources of Ningxia in Nearly Thirty Years. For. Inventory Plann. 35 (5), 98-102. doi:10. $3374 / 014.051 .0103$
Wang, G., Innes, J. L., Lei, J., Dai, S., and Wu, S. W. (2007). ECOLOGY: China’s Forestry Reforms. Science 318, 1556-1557. doi:10.1126/science.1147247

Wang, Y., Yu, P., Feger, K.-H., Wei, X., Sun, G., Bonell, M., et al. (2011). Annual Runoff and Evapotranspiration of Forestlands and Non-forestlands in Selected Basins of the Loess Plateau of China. Ecohydrol. 4, 277-287. doi:10.1002/eco.215

Wang, Y. K., Yang, Q. S., and Guo, S. X. (2014). Changes of Forest Resources in North Slope of Qilian Mountains. Arid Land Geogr. 37 (5), 966-979. doi:10. 13826/j.cnki.cn65-1103/x.2014.05.013

Wang, Y. H., Yu, P. T., Karl-Heinz, F., Wei, X, Sun, G, et al. (2011). Annaual Runoff and Evapotranspiration of Forestlands and Non-Forestlands in Selected Basins of the Loess Plateau of China. Ecohydrology. 4 (2), 277-287. doi:10.1002/eco.215

Wu, Y. Z. (1980). Vegetations in China. Beijing: Science Press. (In Chinese).

Yang, T. B., Wang, S. L., and Yang, W. H. (2014). Construction Organization Design and Cost Estimation of Machine Repair Terraces. Soil and Water Conservation in China 1, 25-27. doi:10.14123/j.cnki.swcc.2014.01.014

Zhang, S. (2015.11.08). The Average Annual Sediment Transport of the Yellow River Is Reduced, and the Water and Soil Loss of the Yellow River Plateau Is Still Serious. Available at: http://www.powerfoo.com/news/sdkx/sdkx2/2015/1110/ 15111084 31072C19H4IDF8F6DA61120.html. [OL]

Conflict of Interest: The authors declare that the research was conducted in the absence of any commercial or financial relationships that could be construed as a potential conflict of interest.

Copyright (®) 2021 Guojing, Junhao and Lihua. This is an open-access article distributed under the terms of the Creative Commons Attribution License (CC $B Y$ ). The use, distribution or reproduction in other forums is permitted, provided the original author(s) and the copyright owner(s) are credited and that the original publication in this journal is cited, in accordance with accepted academic practice. No use, distribution or reproduction is permitted which does not comply with these terms. 